\title{
Study on Knowledge Regarding Various Aspects of Carcinoma Cervix in Rural Areas of Aligarh
}

\author{
Uzma Eram ${ }^{1 *}$, Zakia Sultan ${ }^{2}$
}

${ }^{1}$ Assistant Professor in Department of Community Medicine, J.N. Medical College and Hospital, Medical Rd, AMU Campus, Aligarh, Uttar Pradesh 202002, India

${ }^{2}$ Social Worker in Department of Community Medicine, J.N. Medical College and Hospital, Medical Rd, AMU Campus, Aligarh, Uttar Pradesh 202002, India

DOI: $10.36348 /$ SJM.2019.v04i10.002

| Received: 19.10.2019 | Accepted: 26.10.2019 | Published: 30.10.2019

*Corresponding author: Uzma Eram

\section{Abstract}

Cancer Cervix is the second most common cancer in the world. Cervical cancer is the leading cancer and the leading cause of cancer deaths in women in developing countries. Overall, the mortality rates in developing countries are about four times $(80-85 \%)$ than those in industrialized countries. The aim of this study is to find the knowledge and attitude of cervical cancer among married females of rural areas of Aligarh. The study was a cross sectional study. It was done in July -August, 2019. All the married females were included who gave consent for the study.100 females were included of registered areas of Rural Health and Training Centre, Department of Community Medicine, J.N. Medical College, AMU. Pre-testing of the questionnaire was done on 10 respondents; after which necessary changes were made, and the questionnaire was re-administered. Data entry was done. More than half of the females under study thought vaginal discharge and menstrual irregularity as the main symptoms of cervical cancer. Oral contraceptive pills and multiple sexual partners were considered main risk factors in more than 50 percent of females. Regarding preventive measures, good genital hygiene was known to most of the females under study. Surprisingly, PAP smear was unknown to almost all females under study.

Keywords: Carcinoma cervix, symptoms, risk factors.

Copyright @ 2019: This is an open-access article distributed under the terms of the Creative Commons Attribution license which permits unrestricted use, distribution, and reproduction in any medium for non-commercial use (NonCommercial, or CC-BY-NC) provided the original author and source are credited.

\section{INTRODUCTION}

Cancer Cervix is the second most common cancer in the world [1]. Cervical cancer is the leading cancer and the leading cause of cancer deaths in women in developing countries. One woman dies of cervical cancer every 8 minutes in India [2]. The majority of deaths due to cervical cancer occur in women who were never screened or treated as well as those who had an early sexual debut, a history of multiple sexual partners, and a high number of live births [3]. The highest incidence and mortality rates are in sub-Saharan Africa, Latin America, and South Asia. Overall, the mortality rates in developing countries are about four times (80$85 \%$ ) than those in industrialized countries [4]. The aim of this study is to find the knowledge and attitude of cervical cancer among married females of rural areas of Aligarh. Cervical cancer can be prevented by identifying pre-cancerous lesions early using repeated Pap smear screening and treating these lesions before they progress to cancer. Prevention, early diagnosis and treatment reduce mortality due to cervical cancer. Cervical cancer is a deadly disease once it reaches the invasive stages, but out of all the female genital tract cancers, it is the only preventable cancer if detected at its early stages. Population-based screening with Pap smear is an important secondary preventive measure for cervical cancer that leads to a high-cure rate among cervical cancer patients.

\section{MATERIAL AND METHODS}

The study was a cross sectional study. It was done in July -August, 2019. All the married females were included who gave consent for the study. 100 females were included of registered areas of Rural Health and Training Centre, Department of Community Medicine, J.N. Medical College, AMU. Pre-testing of the questionnaire was done on 10 respondents; after which necessary changes were made, and the questionnaire was re-administered. Data entry was done. 


\section{RESULTS}

Table-1: Knowledge on symptoms of cervical cancer $(\mathrm{N}=100)$

\begin{tabular}{|l|l|}
\hline Symptoms & Numbers \\
\hline Menstrual abnormality & 52 \\
\hline Vaginal discharge & 57 \\
\hline Pain & 31 \\
\hline Vaginal itching & 43 \\
\hline backache & 32 \\
\hline Vaginal sores & 43 \\
\hline Painful sex & 15 \\
\hline Weight loss & 24 \\
\hline Post coital bleeding & 8 \\
\hline Bladder and rectal involvement & 0 \\
\hline
\end{tabular}

Table-2: Knowledge on risk factors of cervical cancer

\begin{tabular}{|l|l|}
\hline Risk factor & $\mathbf{N = 1 0 0}$ \\
\hline Early marriage & 32 \\
\hline Early pregnancy & 35 \\
\hline Repeated pregnancy & 24 \\
\hline OCPs & 62 \\
\hline Multiple sexual partners & 59 \\
\hline
\end{tabular}

Table-3:

\begin{tabular}{|l|l|}
\hline Preventive measures & $\mathbf{N}=100$ \\
\hline Good genital hygiene & 70 \\
\hline Use of condom & 46 \\
\hline PAP test & 1 \\
\hline
\end{tabular}

\section{DISCUSSION}

Regarding the symptoms, as shown in Table-1, more than half of the females under study thought vaginal discharge and menstrual irregularity as the main symptoms of cervical cancer. Pain, vaginal itching and vaginal sores were less commonly known to females under study. Females were also aware of backache and weight loss. In a study conducted in Gujarat [5], regarding knowledge of the symptoms of cervical cancer, $94.2 \%$ respondents stated vaginal discharge as one of the symptoms. The percentages of respondents who mentioned menstrual abnormality and pain as symptoms were 86.9 and 66.6 , respectively. In another study by Nganwai et al., [6], $77.7 \%$ and $92.4 \%$ knew that common symptoms of cervical cancer include post-coital bleeding, inter-menstrual bleeding and abnormal leucorrhoea or bloodstained vaginal discharge. Another study showed similar finding (menstrual abnormality-80.6\%) [7] among female health personnel.

Regarding risk factor as shown in Table-2, oral contraceptive pills and multiple sexual partners were considered main risk factors in more than 50 percent of females. Gujarat study showed [5] that only $11.5 \%$ respondents were aware of multiple sexual partners as one of the risk factors of cervical carcinoma. In a study of Ali et al., [8], 45\% mentioned multiple partners and other promiscuous behaviour as the most common risk factor. In a study carried out by McCarey et al., [9], 41\% of nurses mentioned multiple sexual partners as a risk factor for cervical cancer. In the Gujarat study [5], 73.9\% mentioned early age at pregnancy as one of the risk factors for cervical cancer. Nganwai et al., [6] in their study mentioned that 81.8 and $85.6 \%$ of respondents knew that first sexual intercourse at a young age and having multiple sexual partners were risk factors for cervical cancer.

Regarding preventive measures as shown in Table-3, good genital hygiene was known to most of the females. Surprisingly, PAP smear was unknown to almost all females under study. Gujarat study [5] revealed $88.4 \%$ respondents had knowledge regarding Pap test as one of the preventive measures. Similar findings $(83 \%)$ were documented in a study carried out by Mutyaba et al., [10]. In a study by Ali et al., [8], $75 \%$ knew that Pap smear is the screening test for cervical cancer.

\section{CONCLUSION}

In conclusion, the present findings suggest a very low level of knowledge on cervical cancer, its risk factors and symptoms among the females under study. Hence, the health care associated department should take utmost care to provide the knowledge and encourage them by giving proper health education. The routine method of undergoing the screening test is advised and it has to be inculcated in all aspects of the health care department.

\section{REFERENCES}

1. Kim HW, Kim DH. Awareness of cervical cancer prevention among mothers of adolescent daughters in Korea: qualitative research. BMJ open. 2015 May 1;5(5):e006915.

2. WHO Summary report on HPV \& cervical cancer statistics in India (18/03/2008)

3. Chelimo C, Wouldes TA, Cameron LD, Elwood JM. Risk factors for and prevention of human papillomaviruses (HPV), genital warts and cervical cancer. Journal of Infection. 2013 Mar 1;66(3):207-217.

4. Family Health Division. National guideline for cervical cancer screening and prevention in Nepal, Teku, Kathmandu. 2010. Retrived from http://phaseworldwide.org/wpcontent/uploads/2015/11/Final-booklet-cancergovernment-strategy.pdf

5. Shah V, Vyas S, Singh A, Shrivastava M. Awareness and knowledge of cervical cancer and its prevention among the nursing staff of a tertiary health institute in Ahmedabad, Gujarat, India. Ecancer Medical Science. 2012;6:270-277.

6. Nganwai P, Truadpon P, Inpa C, Sangpetngam B, Mekjarasnapa M, Apirakarn M, Chumworathayi B. Knowledge, attitudes and practices vis-a-vis cervical cancer among registered nurses at the Faculty of Medicine, Khon Kaen University, 
Thailand. Asian Pac J Cancer Prev. 2008 Jan 1;9(1):15-8.

7. Anya SE, Oshi DC, Nwosu SO, Anya AE. Knowledge, attitude, and practice of female health professionals regarding cervical cancer and Pap smear. Nigerian journal of medicine: journal of the National Association of Resident Doctors of Nigeria. 2005;14(3):283-6.

8. Ali SF, Ayub S, Manzoor NF, Azim S, Afif M, Akhtar N, Jafery WA, Tahir I, Farid-ul-Hasnian S, Uddin N. Knowledge and awareness about cervical cancer and its prevention amongst interns and nursing staff in Tertiary Care Hospitals in
Karachi, Pakistan. PloS one. 2010 Jun 10;5(6):e11059.

9. McCarey C, Pirek D, Tebeu PM, Boulvain M, Doh AS, Petignat P. Awareness of HPV and cervical cancer prevention among Cameroonian healthcare workers. BMC women's health. 2011 Dec;11(1):45.

10. Mutyaba T, Mmiro FA, Weiderpass E. Knowledge, attitudes and practices on cervical cancer screening among the medical workers of Mulago Hospital, Uganda. BMC medical education. 2006 Dec;6(1):13. 